\title{
SEMÁNTICA COGNITIVA DIACRÓNICA DE ACOSTARSE ${ }^{\prime}$
}

\author{
JoRge FeRnándeZ JaÉN \\ Universidad de Alicante \\ Jorge.Fernandez@ua.es
}

\begin{abstract}
Resumen
El propósito de este trabajo es presentar un análisis del verbo acostarse realizado con los postulados teóricos de la semántica cognitiva diacrónica, tal y como los expone Geeraerts (1997). Según este modelo, las categorías lingüisticas evolucionan a partir de sus significados más prototípicos o centrales, de los que surgen con el paso del tiempo proyecciones metafóricas o metonímicas que configuran nuevos significados. En este artículo mostraremos esta teoría analizando el verbo acostarse, estudiando su evolución semántica desde su significado latino de costilla (que genera un prototipo direccional) hasta su polisemia actual, en la que prevalece el significado de tumbarse.
\end{abstract}

PALABRAS CLAVE: semántica diacrónica, lingüística cognitiva, teoría de prototipos.

\begin{abstract}
The aim of this paper is to analyse the Spanish verb acostarse, following the theoretical tools established by Geeraerts (1997). From the perspective of Cognitive Semantics, linguistic categories evolve from prototypic to new meanings as a result of metonymic or metaphorical projections along the history of a language. In this way, I will study the evolution of the verb acostarse, from its latin meaning of costilla (which generates a directional prototype) to its current polisemy, in which the meaning of tumbarse prevails.
\end{abstract}

KEY WORDS: diachronic semantics, cognitive linguistics, theory of prototypes.

\section{Introducción}

El objetivo del presente trabajo es presentar un análisis de la evolución semántica del verbo acostarse realizado con los parámetros de la semántica diacrónica cognitiva. Esta metodología se caracteriza, como enseguida veremos, por explicar los cambios semánticos que se dan en los diferentes niveles de la lengua a partir de ciertos conceptos cognitivos como son la metáfora, la metonimia y el concepto de prototipo dentro de una categoría no discreta. Se trata, por tanto, de una metodología de naturaleza psicológica que supera muchas de las limitaciones explicativas que caracterizan a la semántica histórica de corte estructuralista, puesto que el enfoque cognitivo asume que la lengua es algo vivo que está relacionado con

\footnotetext{
$1 \quad$ Este artículo amplía y mejora una versión previa que presentamos en el VI Congreso Nacional de la Asociación de Jóvenes Investigadores de Historiografia e Historia de la Lengua Española en la Universidad de Granada (marzo de 2006) y en el $V$ Congreso Internacional de la Asociación Española de Lingüistica Cognitiva en la Universidad de Murcia (octubre de 2006), en el que obtuvo el premio al mejor trabajo presentado en formato póster. Queremos dar las gracias a los doctores José Luis Cifuentes Honrubia, Leonor Ruiz Gurillo y Sandra Montserrat i Buendia por las observaciones que nos han hecho a propósito de este trabajo.
} 
el entorno, y no un código abstracto e inmanente desconectado de la realidad, como han defendido algunos estructuralistas; consecuentemente, el cambio semántico debe explicarse, en opinión de este modelo, "desde fuera", partiendo de la realidad que verbaliza la lengua y asumiendo que el cerebro humano procesa la información que le llega de esa realidad empleando una serie de mecanismos cognitivos muy concretos, que deben tenerse en cuenta a la hora de describir un cambio semántico específico.

\section{La semántica cognitiva diacrónica}

En 1997, tras muchos años de trabajo, D. Geeraerts publicó su libro Diachronic prototype semantics. A contribution to Historical Lexicology, con el que se puede considerar que empieza de un modo sistemático la primera semántica histórica de naturaleza cognitiva (Soares da Silva, 1998: 279). Lo que defiende este autor es que la evolución del significado de las palabras y estructuras de una lengua no puede explicarse si no se parte de la teoría cognitiva de los prototipos. Esta teoría considera que las distintas categorías con las que podemos clasificar la realidad no son discretas (es decir, totalmente autónomas y susceptibles. de ser definidas a partir de condiciones necesarias y suficientes), sino difusas, por lo que se establecen entre ellas relaciones de contacto. Por ello, las distintas categorías formarían un contínuum en el que habría puntos más focales o prototípicos, lo que explicaría el hecho de que siempre haya elementos más prototípicos o centrales dentro de una categoría y elementos más secundarios o periféricos. Por ejemplo, dentro de la categoría oficio es más probable que en nuestra cultura sea más prototípico médico o carpintero que astronauta o especialista en pirotecnia (Cuenca y Hilferty, 1999: 34-41y Fernández Jaén, en prensa).

Geeraerts toma los efectos de prototipicidad que postula la semántica de prototipos (Kleiber, 1990: 51) y desarrolla a partir de ellos cuatro causas del cambio semántico directamente relacionadas con dichos efectos. Esas causas son las siguientes:

(1) Dentro de una categoría algunos miembros son más representativos que otros ("extensional non-equality").

(2) Los distintos significados de un elemento pueden constituir un grupo de uno o más casos centrales rodeados por significados periféricos que proceden de esos significados centrales ("intencional non-equality").

(3) Hay fluctuaciones a la hora de establecer los límites de una categoría, ya que los límites entre una categoría y otra son siempre difusos ("extensional non-discreteness").

(4) La definición de una categoría, que actúa como núcleo semántico, puede plantear problemas, lo que contradice la hipótesis clásica (seguida desde los trabajos de Aristóteles) según la cual las definiciones se pueden hacer a partir de condiciones necesarias y suficientes ("intencional non-discreteness"). Si esto no fuera así, todas las condiciones de una categoría tendrían el mismo grado de aplicación, y eso no sucede en ningún caso. Por ejemplo, dentro de la categoría ave, la condición puede volar, aunque es muy habitual en muchos de los elementos que se encuentran en esa categoría, no es aplicable a algunas aves, como los pingüinos.

Los dos primeros puntos ponen de manifiesto la importancia que tiene distinguir entre significado central y significados periféricos lo que, diacrónicamente, revela que las categorías nucleares suelen perdurar en el tiempo, mientras se originan a partir de ellas, motivadas 
por metáforas y metonimias (principales mecanismos de categorización según la lingüística cognitiva) nuevas significaciones más abstractas y periféricas, proceso que Geeraerts denomina Semantic polygenesis, y que se relaciona con el tercer efecto de prototipicidad. Por su parte, el cuarto efecto explica el motivo por el que los cambios semánticos están íntimamente relacionados con el saber enciclopédico de los hablantes, puesto que las metáforas y las metonimias que los producen son activadas muy frecuentemente por fenómenos culturales. El siguiente cuadro resume de forma ordenada la propuesta de Geeraerts:

\begin{tabular}{|c|c|c|}
\hline & $\begin{array}{l}\text { EN LA EXTENSIÓN } \\
\text { (En el ámbito de la } \\
\text { referencia) }\end{array}$ & $\begin{array}{l}\text { EN LA INTENSIÓN } \\
\text { (En el ámbito del sentido) }\end{array}$ \\
\hline $\begin{array}{l}\text { NO-IGUALDAD } \\
\text { (Efectos de relevancia, } \\
\text { estructura interna de centro } \\
\text { y periferia) }\end{array}$ & $\begin{array}{l}\text { (a) Diferencias de } \\
\text { relevancia entre los } \\
\text { miembros de una } \\
\text { categoría (diferencia } \\
\text { en el grado de } \\
\text { representatividad) } \\
\text { (1) El cambio semántico } \\
\text { como modulación de } \\
\text { centros prototípicos. }\end{array}$ & $\begin{array}{l}\text { (b) Agrupación de } \\
\text { sentidos por semejanza } \\
\text { de familia y por } \\
\text { sobreposición. } \\
\text { (2) El cambio semántico } \\
\text { como alteración de la } \\
\text { agrupación de sentidos } \\
\text { por semejanza de } \\
\text { familia. }\end{array}$ \\
\hline $\begin{array}{l}\text { NO-DISCRECIONALIDAD } \\
\text { (Problemas de demarcación, } \\
\text { flexibilidad) }\end{array}$ & $\begin{array}{l}\text { (c) Fluctuación en los } \\
\text { límites de una categoría, } \\
\text { ausencia de límites claros. } \\
\text { (3) Cambios semánticos } \\
\text { efímeros (poligénesis } \\
\text { semántica) }\end{array}$ & $\begin{array}{l}\text { (d) Ausencia de } \\
\text { definiciones en términos } \\
\text { de "condiciones } \\
\text { necesarias y suficientes". } \\
\text { (4) Naturaleza } \\
\text { enciclopédica del cambio } \\
\text { semántico. }\end{array}$ \\
\hline
\end{tabular}

Tabla 1. Los efectos de prototipicidad y el cambio lingüístico (Geeraerts, 1997: 22)

La Semantic polygenesis es, en este modelo, el concepto fundamental para entender la flexibilidad de las categorías y el carácter dinámico de su evolución, dinamismo que vendría siempre motivado por la acción de los procesos metafóricos y metonímicos. Además, la Semantic polygenesis explica un fenómeno extraordinariamente curioso: el hecho de que un significado que ha desaparecido dentro de una categoría pueda aparecer de nuevo mucho tiempo después si vuelven a actuar los mecanismos cognitivos que lo hicieron surgir originalmente. Esto se debe a que la Semantic polygenesis "consists of the diachronic discontinuity of peripheral meanings based on the continuous transmission of the more salient readings of a lexical item" (Geeraerts, 1997: 65). El hecho de que los significados más centrales o prototípicos suelan perdurar sin demasiadas alteraciones en el tiempo explica que permanezca latente el sustrato cognitivo que hizo aparecer un nuevo significado en un momento dado de la historia, y esa latencia es la que permite que ese significado periférico 
pueda reaparecer en cualquier momento, aunque haga siglos que no se emplea. Geeraerts ejemplifica este fenómeno con el verbo neerlandés verduisteren, que siginificó hasta el siglo XVII hacer desaparecer, significado que resurge espontáneamente a finales del siglo XX sin que se pueda relacionar con ninguno de los significados actuales de ese verbo (Geeraerts, 1997: 62-68).

Por otro lado, cabe hacerse una pregunta; si las categorías son flexibles, ¿qué es lo que limita la formación de los significados? ¿Existe alguna pauta para que la creación de nuevos sentidos no sea azarosa? Según Geeraerts, lo que hace que el origen de los nuevos significados no sea totalmente arbitrario e impredecible es la presencia del significado prototípico o central (que puede cambiar, como veremos, con el paso del tiempo); siempre debe haber algún contacto entre los nuevos significados y el prototipo, sea directo o indirecto, lo que hace que entre los distintos significados se establezcan semejanzas de familia ${ }^{2}$. Por tanto, reconstruir la evolución semántica de una categoría equivale según la semántica diacrónica cognitiva a reconstruir la red semántica progresiva de sus sucesivas extensiones metafóricas y metonímicas a partir de los significados más centrales, que suelen permanecer invariables.

La propuesta de Geeraerts se completa con unos principios generales para explicar las fusiones prototípicas y la polisemia. De estas ideas destaca el principio según el cual cuando un significado resulta difícil de poner en relación con su prototipo (porque las semejanzas de familia se han debilitado demasiado) tiende a desaparecer.

En definitiva, el trabajo de Geeraerts ofrece un sistema explicativo sistemático y coherente (inspirado en los paradigmas científicos de $T$. Kuhn) para reconstruir y estudiar la semántica diacrónica de cualquier categoría lingüística, siempre y cuando se disponga de un corpus documental lo suficientemente amplio de dicha categoría con el que poder demostrar empíricamente los procesos de extensión metafórica y metonímica. Además, esta teoría demuestra que el cambio semántico tiene mucho que ver con el modo de percibir la realidad que tiene el Ser Humano y con la lógica intrínseca que dicha realidad le impone al lenguaje. Por todas estas razones, los presupuestos de la semántica cognitiva diacrónica superan algunas de las limitaciones teóricas de la semántica diacrónica estructural; a diferencia de ésta, la semántica histórica cognitiva tiene en cuenta no sólo el significado de las palabras, sino también el significado de las estructuras sintácticas (dado que el significado se entiende como una conceptualización) y además utiliza el conocimiento del mundo que poseen los hablantes y los factores culturales de la sociedad para explicar los cambios, algo que no es habitual en los modelos más objetivistas ${ }^{3}$.

2 Esto significa que los distintos elementos de una categoría no tienen por qué parecerse al elemento nuclear, sino que pueden relacionarse con otros más periféricos, por lo que las relaciones entre los elementos pueden ser mediatas o inmediatas, como sucede con las familias "reales"; los hijos se parecerán más a los padres que a los abuelos, y los nietos se distinguirán aún más de los abuelos que de los padres, etc. Con todo, la relación "genética" entre todos los elementos siempre se podrá reconstruir históricamente, por mucho que se diluyan las semejanzas de familia. Véase el trabajo de Garachana y Hilferty (1994) para esta cuestión.

3 No obstante, hay que señalar que algunos trabajos han intentado compatibilizar ambos modelos, y que el propio Geeraerts ha reflexionado sobre la posible complementariedad de la semántica estructural y de la semántica de prototipos. Pueden verse para esta cuestión los trabajos de Le Clerc (1998) o García Jurado (2003 y 2006). 


\section{Origen y polisemia de acostarse}

Para llevar a cabo nuestro análisis del verbo acostarse siguiendo el modelo que acabamos de ver, hemos de tener en cuenta dos cosas; primero, cuál es el origen etimológico de este verbo y segundo, cuántos significados distintos ha tenido a lo largo del tiempo. La etimología es fundamental por una razón muy sencilla; para reconstruir la evolución semántica de cualquier elemento es necesario conocer de dónde procede, conocimiento imprescindible para poder rastrear las distintas innovaciones semánticas que se han producido a partir del significado originario y del étimo del que éste surge. En cuanto a la polisemia, se trata de una información fundamental para poder determinar cuántas ramificaciones semánticas ha experimentado ese elemento con el paso de los siglos.

El verbo acostarse es un término creado a partir del latín; surge de fusionar la preposición latina $a$ y el sustantivo costa,-ae. La preposición dota al conjunto de un marcado carácter direccional, puesto que en latín esta preposición introducía estructuras que indicaban fundamentalmente, lugar o punto de partida, lugar de donde, origen, procedencia, punto de distancia y tiempo a partir del cual ${ }^{4}$. Por su parte, costa,-ae tenía en latín dos significados: costilla y costado de una nave o embarcación. Acostarse, por consiguiente, nace como un verbo relacionado semánticamente con los desplazamientos y con una parte física del cuerpo o de una embarcación, lo que activará motivaciones metafóricas muy interesantes, decisivas en su evolución.

En cuanto a la polisemia de nuestro verbo, hemos podido determinarla analizando el corpus diacrónico que hemos elaborado para nuestro estudio. Utilizando la base de datos CORDE (Corpus Diacrónico Del Español) ${ }^{5}$, hemos preparado un corpus histórico compuesto por un total de 1405 ocurrencias, que abarcan usos de acostarse desde finales del siglo XII hasta finales de la década de los 70 del siglo XX. Hemos de precisar que sólo hemos empleado documentos de España y que hemos utilizado todo tipo de textos, desde los literarios hasta los científicos.

Pues bien, a la luz de nuestros datos, comprobamos que nuestro verbo ha tenido a lo largo del tiempo los siguientes significados: acercarse a un lugar fisico, acercar algo a un lugar fisico, acercarse a un lugar no fisico o a un concepto, llegar a la costa, tumbarse, inclinarse, mantener relaciones sexuales con alguien, ladearse un edificio o construcción y tumbar algo o a alguien ${ }^{6}$. Algunos de estos significados están totalmente vigentes en español, otros han desaparecido completamente (aunque muchos diccionarios insistan en mantenerlos en sus entradas) y otros perviven, aunque se emplean muy poco. Lo interesante es que estos significados parecen demasiado variados como para tener un origen común; ¿qué los relaciona?, ¿han surgido todos a partir de un único significado? ¿hay alguna lógica

4 Este valor locativo y direccional de la preposición a se mantiene en el español actual. Por ejemplo, es habitual que introduzca complementos locativos y direccionales (sobre todo acompañando a verbos de dirección como mirar), e incluso cuando se supone que sólo tiene valor diacrítico, tiende a mantener cierta semántica locativa, lo que hace, por ejemplo, que no haya límites fronterizos claros entre los CD preposicionales y los CC de Lugar.

5 Esta base de datos se puede consultar en la página web www.http://corpus.rae.es.

6 Algunos diccionarios, como el DRAE (2001), recogen otro valor de acostarse que no hemos documentado en nuestro corpus: "Dicho de una balanza: Pararse en posición en que el fiel no coincida con el punto o señal de equilibrio" (DRAE, 2001: 36). 
que explique esta diversidad? Si la tesis de Geeraerts es correcta, un estudio histórico nos permitirá establecer cuáles son las semejanzas de familia entre estos significados y en qué lugar de la historia han surgido.

\section{Prototipos y evolución, metáforas y metonimias}

Después de analizar las 1405 ocurrencias de nuestro corpus y de organizarlas por siglos, obtenemos un cuadro que permite reconstruir la evolución de nuestro verbo. Como es lógi$\mathrm{co}$, hemos de suponer que los nuevos significados no surgen de un modo súbito e inesperado, sino que se van formando de un modo gradual, siguiendo, en este sentido, las pautas evolutivas que defiende la gramaticalización. Por otro lado, es esperable que no coexistan en el mismo período de tiempo significados muy alejados, ya que el efecto de las proyecciones metafóricas y metonímicas es lento y progresivo. Por último, debemos tener muy presente que la escritura es siempre posterior al habla y que los corpus únicamente ofrecen muestras orientativas; por ello, aunque de un significado haya poca documentación en un determinado momento, hemos de suponer que en la lengua oral su uso ya debería estar bastante asentado. El resultado de nuestro análisis puede verse en la tabla siguiente, que muestra cuántas ocurrencias hay de cada significado en cada siglo?

\begin{tabular}{|l|l|l|l|l|l|l|l|l|l|}
\hline Sdos & XII & XIII & XIV & XV & XVI & XVII & XVIII & XIX & XX \\
\hline A & 0 & 34 & 74 & 18 & 25 & 5 & 0 & 0 & 0 \\
\hline B & 3 & 2 & 2 & 9 & 1 & 1 & 0 & 0 & 0 \\
\hline C & 0 & 7 & 16 & 26 & 18 & 0 & 0 & 0 & 0 \\
\hline D & 0 & 0 & 1 & 2 & 9 & 5 & 0 & 0 & 1 \\
\hline E & 0 & 2 & 8 & 41 & 157 & 149 & 23 & 222 & 339 \\
\hline F & 0 & 2 & 0 & 2 & 5 & 0 & 0 & 0 & 0 \\
\hline G & 0 & 0 & 1 & 3 & 4 & 2 & 2 & 1 & 88 \\
\hline H & 0 & 0 & 0 & 0 & 1 & 0 & 0 & 0 & 0 \\
\hline I & 0 & 0 & 0 & 0 & 18 & 16 & 1 & 27 & 32 \\
\hline
\end{tabular}

Tabla 2. Agrupación de significados por siglos.

Gracias a esta información podemos reconstruir diacrónicamente la evolución de acostarse siguiendo el modelo de la semántica cognitiva diacrónica. Lo primero que observamos es que durante los siglos XII, XIII y XIV el significado principal y más frecuente de acostarse era el significado A (llegar a algún lugar fisico), es decir, comprobamos que gracias a la herencia latina, nuestro verbo significaba originariamente algo así como acercar la costilla 
a algún lugar ${ }^{8}$, o lo que es lo mismo, ir o desplazarse fisicamente a un lugar. Por tanto, nuestro verbo es, en su origen, un verbo de dirección o movimiento direccional (Cifuentes Honrubia, 1999: 435-443), por lo que su prototipo semántico es el significado A. Veamos algunos ejemplos:

(1) Non querades ser assí como el cauaillo y el mulo en que no ha entendimiento con el muesso \& con el fresno, aprieta las boccas d'eillos por que no se acuesten a ti. (Hermán el alemá, Traslación de Psalterio, 1240-1272).

(2) Mas quando el se acosto a Italia, su piensa fue pacificada, \& considero el blasmo de su muier, \& le enuio letra de diuorçio. (Juan Fernández de Heredia, Traducción de Vidas paralelas de Plutarco, 1379-1384).

(3) E como se acostassen a la casa aquella en do fazien la obra subtosament, tanta claredat resplandio dentro la casa que oyxos de hombre no lo podien guardar por sobre grant claredat. (Anónimo, Obra sacada de las crónicas de San Isidoro, de Don Lucas, Obispo de Tuy, 1385-1396).

(4) - He miedo que vengan empós de nos e que nos alcancen; e si nos alcançan, seríamos en peligro de muerte e quanta diligencia feísmos sería perdida. E por esto tengo por bien que andemos quanto la noche durare; e quando fuere de día, algún castillo podremos fallar do nos acostemos e estemos seguros. (Anónimo, El baladro del sabio Merlín con sus profecias, 1400-1498).

(5) Mostró, como oyó esto, moverse de su asiento un poco Juliano; y como acostándose hacia Marcelo, y mirándole con alegre rostro, le dijo: - Ahora me place más el haberos, Marcelo, acordado lo que olvidábades [...]. (Fray Luis de León, De los nombres de Cristo, 1583).

Por tanto el significado A va a ser el núcleo de la categoría (con un significado direccional) a partir del cual va a iniciarse la ramificación semántica de este verbo. Pero este significado prototípico original va a convivir desde el principio con otro significado menos prototípico, aunque también con valor direccional: el significado B (acercar algo a un lugar).

En efecto, cuando pensamos en la escena o modelo cognitivo ${ }^{9}$ que activa un significado como acercarse (que es el que tiene A), imaginamos un elemento (sujeto) que se acerca a un lugar (meta), estructura conceptual mucho más prototípica que la que representa una

8 Es muy frecuente que las palabras se distancien semánticamente de sus étimos debido a proyecciones metafóricas, como sucede en este caso. El significado de costilla de costa,-ae será el que prevalecerá en el caso de acostarse (por encima de lado de una embarcación) y será a partir de él del que surgirán los nuevos valores metafóricos fundamentales. Para revisar las principales proyecciones metafóricas que se han dado en el léxico patrimonial del español a partir del latín véase el excelente libro de Santos Domínguez y Espinosa Elorza (1996).

9 Un modelo cognitivo es una representación mental de cómo se organiza el mundo (Cuenca y Hilferty, 1999: 70). Se trata de un concepto fundamental en el marco de la lingüística cognitiva ya que según sus planteamientos, el significado es una conceptualización de la realidad, es decir, la formalización mental del funcionamiento de la realidad. Debido a esta tesis, el significado no se halla únicamente en las palabras, sino que se encuentra también en la sintaxis, puesto que cada oración distinta activará un modelo cognitivo diferente. El concepto de modelo cognitivo ha recibido diversas denominaciones (con mínimas diferencias teóricas), como frame (Fillmore), modelo cognitivo idealizado (Lakoff), esquema mental (Pottier), o mapping (Fauconnier). Para un análisis de estos conceptos, véase el libro de Ungerer y Schmid (1996: 205-249). 
escena en la que algo (sujeto) acerca algo (CD) a un lugar (meta) ${ }^{10}$. Esta posibilidad, que constituye un significado independiente del significado $\mathrm{A}$, es mucho más extraña (como lo demuestra su escasa frecuencia de aparición en el corpus) ya que el movimiento tiende a configurarse con verbos intransitivos. No obstante, como señalábamos antes, encontramos ejemplos de $\mathrm{B}$ ya en las primeras documentaciones de acostarse, y de hecho hemos podido hallar tres casos de finales del siglo XII (un poco anteriores a los primeros ejemplos de A). Veamos algunos ejemplos de este significado:

(6) Qvi su casa quisiere acostar o arrimar a paret de otro o arrimar sobrella, de primero meytad del preçio que costo la paret; desend arrime $\&$ acueste su casa a la paret o armar sobre ella, si la paret fuere en rrayz de comun; ca si de comun non fuere, non puede labrar sobre ella paret nj acostar nj arrimar, si de señor dela paret non quisiere. (Anónimo, Fuero de Soria, 1196).

(7) Et después a pocos dias. una noche que fazie muy oscura. escuchamos les que rodeauan. $\&$ guardauan la hueste [...]. Tomaron entonces una escalera \& descendieron la. a la cercaua \& después acostaron la. a la torre. (Anónimo, Gran Conquista de Ultramar, 1293).

(8) E quando fuere bien remojada metan las manos en ella e freguen la bien fasta ques descortese de la cortesa anneja e que finquen limpia e clara atal como la simiente de los figos e fagan vna talega de paño de lana e metan y la simiente. E pongan la al sol e acuesten la a vna parte por tal ques corra el agua e cubran la con unas touajas de yuso e el otro de suso. (Anónimo, Tratado de Agricultura de Ibn Bassal, 1300).

(9) E el caballero de Tormelida metio su lanza en piezas E Lanzarote le firio tan rreçia mente que el muj presto ido lo figa que el fierro e vna pieza del asta non pareçiese dela otra parte porlas espaldas $\mathrm{E}$ pusolo tan lueñe del caballo quanto le duro la lanza $\mathrm{E}$ paso porel $E$ saco su lanza sana del $E$ fuese a vn arbol que ay estaba en medio del canpo $E$ acosto alli su lanza $\mathrm{E}$ apeose del caballo (Anónimo, Traducción de Lanzarote del Lago, 1414).

(10) Pues ella asi como prudentísima leyendo la voluntad del hijo como quier que non hallaua dezia le asi. Fijo mio bendito \& mi dios si tu quieres que yo no llore non llores tu. Ca yo en otra manera non me podria retener. \& alimpiauale el rrostro conel su velo \& los ojos \& acostaua el rrostro del hijo al suyo \& dauale la leche $\&$ asi lo gouernaua con toda la diligencia que ella sabia \& podia. (Anónimo, Libro llamado Infancia Salvatoris, 1493).

Aparte de este significado relacionado con una conceptualización del movimiento poco prototípica, el significado A coexiste desde el siglo XIII con otro significado que consiste

10 En opinión de Talmy (1985: 62), hay cuatro elementos fundamentales en una escena prototípica de movimiento: la FIGURA, el FONDO, el MOVIMIENTO, y el TRAYECTO. A estos elementos se les pueden añadir otros dos, de carácter opcional: la MANERA y la CAUSA. Como se ve, el movimiento genera de modo natural una conceptualización intransitiva, en la que un OBJETO desplazado por la FIGURA resulta inusual. De hecho, acostarse (con el significado de acercarse) se puede incluir dentro de la categoría de los verbos de dirección inherente, verbos que se caracterizan por su naturaleza esencialmente intransitiva. Para la cuestión de la conceptualización del movimiento y sus relaciones con la transitividad véase el trabajo de Batsiukova (2004). 
en una proyección metafórica relacionada con el lugar al que se acerca el sujeto; de A surge, por tanto, el significado $\mathrm{C}$, en el que, por la acción de una metáfora ontológica (Lakoff y Jonson, 1986: 63-70), la meta del movimiento deja de ser un lugar físico para pasar a convertirse en un lugar abstracto o un concepto. Gracias a este nuevo significado, acostarse va a poder expresar una gran variedad de contenidos, sobre todo de tipo atributivo ${ }^{11}$. Veamos algunos ejemplos:

(11) Ujo vn colpe que fizo don Roldane, ujdo a don Roldan acostado a un pilare, como se acosto a la ora de finare. (Anónimo, Roncesvalles [Documentos Lingúísticos Navarros], 1230).

(12) Aquel consentia solo a la ley, no pas porque amasse mucho de Pompeyo, mas porque del principio siempre el se acostaua a la amjgança del pueblo. (Juan Fernández de Heredia, Traducción de Vidas paralelas de Plutarco, 1379-1384).

(13) El cuarto conssejo quel señor da a los medicos \& muy comodioso a ssus anjmas es que siempre sse acuesten al penssamjento artificial \& no al uocal nominal. (Estéfano de Sevilla, Visita y consejo de médicos, 1400).

(14) -Agora no me maravillo de lo que ha fecho, que cierto a la su bondad ninguno se acuesta. (Anónimo, Palmerán de Olivia, 1511).

(15) Pues como la voluntad tenga este señorío sobre todo el hombre, y el amor lo tenga sobre la voluntad [...] síguese que á donde se acostare el amor, allí se acostará la voluntad, y eso abrazará todo el hombre con todo lo que hay dentro de su reino, y así vendrá á ser tal cual fuere aquello que ama. (Fray Luis de Granada, Adiciones al Memorial de la Vida Cristiana, 1574).

Pero además de esta proyección metafórica al terreno de lo abstracto, el prototipo A también adquiere desde muy pronto otro significado periférico debido a la acción de la metonimia y a la influencia del segundo significado latino de costa,-ae (costado de una nave): nos referimos al significado D (llegar a la costa) que en nuestro corpus se empieza a documentar en el siglo XIV. Este significado aparece porque, de todos los lugares que pueden ser meta de acostarse, el lugar metonímicamente más relevante es la costa y, por extensión, el puerto o cualquier otro lugar al que puedan dirigirse las embarcaciones ${ }^{12}$. Se trata de un significado poco documentado $o^{13}$ pero que pervive en la actualidad en los ámbitos marineros. Veamos algunos ejemplos:

(16) Lo mismo hicieron todos los marineros, visto que el Almirante reposaba y que la mar era calma. El Almirante se había acostado por estar seguro de bancos y de peñas, porque

\footnotetext{
11 Por ejemplo, la oración Pedro se acuesta a la virtud equivale semánticamente a Pedro es virtuoso.

12 Es decir, en lugar de acercar la costilla, se acerca el costado de la embarcación, y por tanto, una meta concreta (costa o puerto) pasa a ser el destino único (metonimia de parte por el todo).

13 De hecho es en el siglo XVI cuando más documentación de este uso se encuentra, algo nada extraño teniendo en cuenta que es la época de la colonización del Nuevo Mundo y que muchos marinos y aventureros escribieron diarios de navegación que hoy conservamos. Esto demuestra que los factores culturales y enciclopédicos están relacionados con la semántica (factor (4) de la teoría de Geeraerts, 1997).
} 
cuando el domingo envió las barcas al rey Guacanagarí habían visto la costa toda los marineros y los baxos que había y por dónde se podía pasar desde aquella punta al pueblo del rey dicho, lo que no habían hecho en todo el viaje. (Fray Bartolomé de las casas, Historia de las Indias, 1527-1561).

(17) Y pasarás por este camino del sudueste una legua Della; y no te acuestes más a la isla, porque della salen algunos bancos que tienen 6 y 5 y 7 brazas. (Hernando de la Torre, Derrotero del viage y navegación de la armada de Loaisa desde su salida de la Coruña, 1528).

(18) En esto se acostó á tierra, y saltando en ella el barquero ayudó a Grisolfo á tomar el caballo de su señor. (Jerónimo de Urrea, Primera parte del libro del invencible caballero don Clarisel de las Flores, 1574).

(19) Tomaron la derrota la vía del oeste o poniente, y en siete grados escasos de altura descubrieron tierra, y acostando a ella vieron el sur de la isla. (Luis Cabrera de Córdoba, Historia de Felipe II, rey de España, 1619).

Por tanto, en su primera fase evolutiva, acostarse era un verbo direccional con un prototipo semántico del que surgían tres significados periféricos; uno que expresaba un movimiento direccional no prototípico de tipo transitivo, otro con una meta metafórica y otro con una meta metonímica. Pero además de los significados $\mathrm{B}, \mathrm{C}$ y D, de A empieza a surgir un nuevo significado (documentado ya tímidamente en el siglo XIII) que va a ser decisivo en la evolución de nuestro verbo; nos referimos al significado $\mathrm{E}$ (tumbarse).

En efecto, la imagen metafórica original de acercar la costilla a un sitio conceptualiza una escena en la que un sujeto lleva su costilla (es decir, se lleva a sí mismo, ya que la costilla es una parte inalienable del sujeto) hacia un lugar (idea de desplazamiento direccional por antonomasia). Pero de ese significado prototípico pronto va a surgir una variante que no implica desplazamiento direccional, sino sólo movimiento en un punto fijo con ausencia de trayectoria; esto se debe a que el nuevo significado $\mathrm{E}$ va a añadir un matiz que no se encuentra en A: la costilla se desplaza para que toque físicamente la meta ${ }^{14}$. En una situación prototípica ${ }^{15}$ llevar la costilla hacia un lugar para que entre en contacto físico con él implica tumbarla en el suelo (verticalidad), no llevarla a través del espacio hacia un lugar (horizontalidad). Por este motivo, a partir de A surge E, significado nuevo que elimina el valor direccional para focalizar el hecho de tumbar el cuerpo en el suelo o en cualquier otra

14 Este matiz es posible porque los verbos direccionales pueden localizar el origen del movimiento, la trayectoria o la meta. En este caso se localiza la meta y se percibe que ésta puede estar orientada hacia abajo, orientación que, por efecto de una metonimia, se hace total, por lo que la idea de trayectoria desaparece.

15 Para entender el concepto de situación prototípica podemos recurrir al ejemplo clásico de Kleiber (1990: 10). Imaginemos la escena que activa la siguiente oración: La pelota está debajo de la mesa. Ante esta frase, y debido a nuestro conocimiento del mundo, todos imaginamos una mesa de cuatro patas perfectamente ubicada debajo de la cual se encuentra una pelota. Sin embargo, sería igualmente posible que la mesa estuviera volcada y que la pelota se encontrara aplastada por la superficie de la mesa. No cabe duda de que en ambos casos la pelota está debajo de la mesa, pero lo más esperable y prototípico es que se dé la primera situación y no la segunda. Casos como éste demuestran que la configuración sintáctico-semántica de las lenguas refleja icónicamente nuestra visión directa del mundo y que tiende a formalizar los casos más habituales. Para otros ejemplos similares relacionados con el punto de vista y la gramática véase Langacker (1987: 122-126). 
superficie con el motivo que sea (dormir, prototípicamente). Este nuevo significado guarda con respecto al prototipo A la idea de movimiento, pero se trata de un movimiento no direccional muy diferente. Veamos algunos ejemplos:

(20) Y assi mesmo desta manera hazian las falsas profetissas almohadas y cabezales haziendo que los hombres se acostasen sobre ellos diziendo asi podres dormir segura y sosegadamente sin njngunt temor (Anónimo, Biblia romanceada, 1400).

(21) Como fue hora de dormir, acostándose en sus lechos, passaron esa noche más despiertos que dormidos, no viendo la hora que de día fuesse [...]. (Feliciano de Silva, Lisuarte de Grecia, 1514).

(22) Levantaron las mesas, y todos dijeron a don Diego que se acostase. Él quería pagar la cena, y replicáronle que no lo hiciese, que a la mañana habría lugar. (Francisco de Quevedo, La vida del Buscón llamado Don Pablos, 1626).

De este nuevo significado van a surgir a su vez otros significados distintos que van a guardar con respecto al prototipo relaciones indirectas de semejanza semántica. Ya en el siglo XIII se documenta otro significado que no procede de $\mathrm{A}$, sino de $\mathrm{E}$; se trata del significado $\mathrm{F}$ (inclinarse). En este caso el significado consiste en un movimiento más sutil que en $\mathrm{E}$, ya que el desplazamiento hacia abajo no llega a culminarse; el sujeto parece que se va a tumbar pero, finalmente, sólo se inclina (metonimia de parte por el todo). Veamos algunos ejemplos:

(23) Et sea aquella tierra llana deguisa que se non acueste ell estrumente a ninguna parte por tal que se non pierda la parte del zonte. (Rabí Zag, Libros de la lámina universal, 1277).

(24) Aconteció que queriendo Hieronimo bomitar se puso de pechos colgando sobre el mar: y como los vientos se enfortaleziessen, el navio se acosto mucho en aquella parte tanto que con la fuerza del ayre cayo de cabeza en el agua. (Cristóbal de Villalón, $E l$ Scholástico, 1539).

(25) A lo sexto digo que se debe mirar que la sphera o gonces en que la dicha caxa anda metida, sobre que se sustenta, esté tan buena y ligera, que la dicha caxa ande siempre igual. En tal manera que, aunque la nao penda o se acueste a una vanda o a la otra, la dicha caxa y rosa estén contino derechas [...]. (Pedro de Medina, Arte de navegar, 1545).

(26) Y luego en su presencia llamé al Alonso Alvarado e le dije que no se quitase de aquella puente e que pasase por ella la gente de guerra, sin dejar pasar ningún bagaje hasta tanto que estuviese toda de la otra banda, porque no se nos acostase la puente y se nos desbaratase, y los caballos se echasen al río, como ya se habían comenzado a echar ese mismo día. (Pedro de Valdivia, Cartas que tratan del descubrimiento y conquista de Chile, 1550).

Pero además del significado F, desde el siglo XIII E va a ser el significado periférico más empleado, por lo que empieza a generar otras variantes, caracterizadas en todos los casos por carecer de la idea de movimiento direccional. 
En el siglo XIV surge de E otro significado nuevo, originado también a partir de una metonimia; se trata del significado $\mathrm{G}$ (mantener relaciones sexuales con alguien) ${ }^{16}$. Es evidente que un determinado sujeto puede realizar la acción de tumbarse acompañado por alguien (persona que estará representada en la oración por un CC Comitativo o de Compañía); pero debido a que el acompañante prototípico con el que alguien puede acostarse es su amante, se origina una variante a partir de $\mathrm{E}$ que focaliza mediante una metonimia de parte por el todo a la persona con la que el sujeto se acuesta (amante) y la intención (no dormir, sino mantener relaciones), con lo que el verbo pasa a significar mantener relaciones sexuales. Podemos ver unos ejemplos a continuación:

(27) Vós, Brangel, es menester que os acostéis esta noche con el rey, e abrá vuestra virginidad. (Anónimo, Tristán de Leonis, 1501).

(28) Ajustada conforme a su deseo / en la primera noche de himeneo / se acostó con su novio muy gustosa / sin temor la doncella melindrosa. (Félix M. de Samaniego, El jardín de Venus, 1797).

(29) Y después pensó tambaleándose, con la imaginación puesta en Isabel y en Carlos: "ii Y se acostarían juntos, como el jardinero y su mujer!!". (Enrique Jardiel Poncela, Pero... ¿hubo alguna vez once mil vírgenes? 1931).

En el siglo XV, como se puede apreciar en la tabla 2, el empleo del significado E se dispara, al tiempo que el prototipo A empieza a debilitarse. Cuando esto sucede, normalmente se produce lo que se conoce como un cambio de prototipo (Montserrat i Buendía, 2004: 421-442), que es precisamente lo que pasa con acostarse; el núcleo de la categoría pasa a ser $\mathrm{E}$ en el siglo XV, por lo que los significados A, B y C (es decir, los significados con contenido direccional ${ }^{17}$ ) empiecen a utilizarse mucho menos, lo que los hará desaparecer con el paso del tiempo. Por otro lado, el significado E aún genera dos significados más en el siglo XVI. Por un lado, se da el significado $\mathrm{H}$. Se trata de un valor utilizado sobre todo en el ámbito de la arquitectura, ya que expresa el contenido ladearse un edificio o construcción. También en este caso el movimiento vertical es mínimo y el sujeto no llega a tocar el suelo, lo que se explica cognitivamente del mismo modo que el significado $\mathrm{F}$, es decir, por la acción de una metonimia de parte por el todo; un mínimo movimiento dentro del movimiento completo necesario para que el sujeto se tumbe es expresado con todo el verbo. En nuestro corpus sólo hemos documentado un caso (a pesar de que muchos diccionarios registran este significado), aunque es perfectamente posible que haya muchos más en los textos escritos, pues este significado aún existe en el español actual. Veamos nuestro ejemplo:

16 Como se puede apreciar en la Tabla 2, la documentación escrita de este significado es muy escasa antes del siglo XX, lo cual puede deberse a que se trata de un significado tabú. De hecho, la mayoría de ejemplos medievales de este valor se encuentran en traducciones de textos árabes, algo que quizá se explique por las diferentes formas de entender el amor que se dan entre la cultura árabe y la cultura católica. Para la influencia de los tabúes y de los eufemismos en la configuración semántica véase el trabajo de Martines (2000).

17 El significado $\mathrm{D}$ es el único valor con contenido direccional que aún se empleará en español a partir del siglo XVII. 
(30) El suelo se cabe muy alto para que no le toque el sarro quando lo xaharen, ni con el pavimento, que es el suelo quando lo solaren; porque, quando están soterrados, con la vejez se marchitan y arrugan, y después, assentando encima, se acostan, y assí rompen el enluzimiento de las paredes. (Miguel de Urrea, Traducción de la Arquitectura de Marco Vitruvio Pollión, 1582).

El último significado que deriva de $\mathrm{E}$ es el significado I (tumbar algo o a alguien), variante transitiva no pronominal de $\mathrm{E}$. Al igual que sucedía con el significado $\mathrm{B}$ con respecto a $\mathrm{A}$, aquí se mantiene el contenido semántico intacto y sólo se altera la conceptualización de la escena; de un elemento que se tumba a sí mismo, pasamos a un sujeto que tumba algo o a alguien (CD). Se trata de una conceptualización menos prototípica y, por lo tanto, más periférica dentro de la categoría, aunque hay que señalar que es bastante empleada en la actualidad, sobre todo en el contexto de acostar a niños o a personas enfermas. Veamos algunos ejemplos:

(31) Y como ya fue llegada la ora de se ir a dormir, Arnida se despidió de la infanta, y Fidelia la llevó a su aposento, adonde la acostó en su lecho. (Diego Ortúñez de Calahorra, Espejo de principes y caballeros, 1555).

(32) Entendiendo aquellas altas dueñas el mal de la Princesa y como le aquexauan los dolores, conoçieron ser arribada la ora del parto, y en un punto finieron de ramas verdes y tiernas flores de los prados vn lecho, donde acostaron a la Princesa [...]. (Jerónimo de Urrea, Primera parte del libro del invencible caballero don Clarisel de las Flores, 1574).

(33) Perico Hernández y Nieves habían acostado a los chicos. Por fin reposaban ante su casa apenas oyendo entre el sueño que llegaba después del cansancio de todo el día. (Enrique Nácher, Guanche, 1957).

Con todos estos datos, ya estamos en condiciones de ofrecer la reconstrucción de la red semántica que acostarse ha trazado a lo largo del tiempo a partir de su origen latino ${ }^{18}$, red que muestra el cambio de prototipo que se da en la categoría en el siglo XV y las semejanzas de familia que se establecen entre los distintos significados. Las líneas discontinuas que salen de los significados indican hasta cuándo se ha empleado cada uno:

18 Aunque no hemos hallado ningún ejemplo de A anterior al siglo XIII, lo ubicamos dentro de la red en el siglo $\mathrm{XI}$ porque es obvio que fue el primer significado de la categoría y que ya debía emplearse en español en ese siglo. Además, el hecho de que sí hayamos encontrado ejemplos de B en el siglo XII (significado mucho más periférico) confirma esta hipótesis, puesto que no es posible que un significado muy periférico sea anterior al prototipo del que parte. 


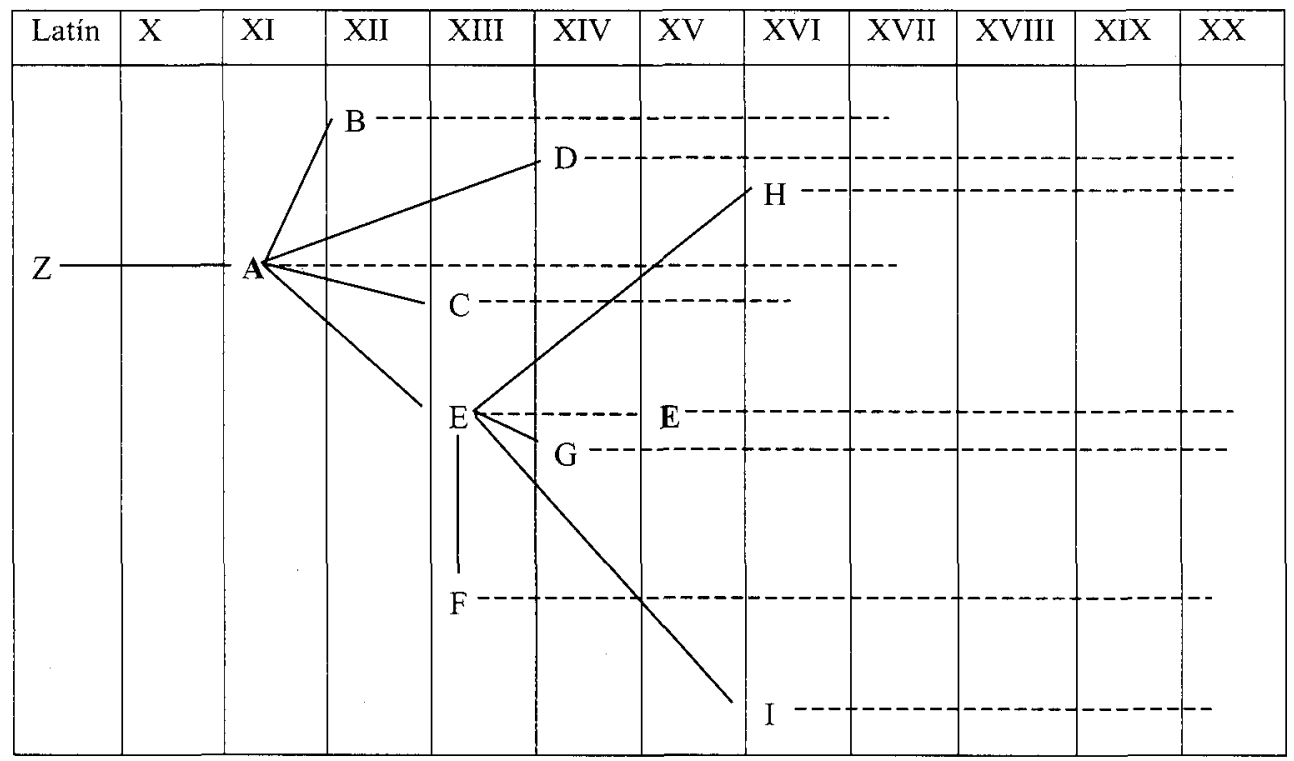

Tabla 3. Red semántica de acostarse.

$\mathrm{Z}: a+$ costa,-ae (latín)

A: acercarse a un lugar fisico (primer prototipo)

B: acercar algo a un lugar fisico

C: acercarse a un lugar no fisico o a un concepto

$\mathrm{D}$ : acercarse a la costa, atracar

E: tumbarse (segundo prototipo)

F: inclinarse

G: mantener relaciones sexuales con alguien

$\mathrm{H}$ : ladearse un edificio o construcción

I: tumbar algo o a alguien

\section{Reanálisis sintáctico y cambio de conceptualización}

Como hemos visto al analizar la evolución semántica de acostarse, el cambio de prototipo que se da en el siglo XV hace que de una conceptualización horizontal (idea de dirección con desplazamiento) se pase a una conceptualización prototípica vertical (movimiento sin desplazamiento). Estas diferentes conceptualizaciones van a alterar también la sintaxis de acostarse, que pasará de ser un verbo direccional en una primera época, a ser únicamente un verbo de movimiento. Las diferencias sintácticas entre los verbos de dirección o desplazamiento y los verbos de movimiento son las siguientes (Cifuentes Honrubia, 1999: 437-439):

a) El complemento de lugar (lo que en la teoría de Talmy se llama FONDO) es obligatorio en los verbos direccionales, y opcional en los verbos de movimiento. 
b) Los verbos de desplazamiento pueden combinarse con complementos locales que indiquen origen, llegada, o ambos (idea de trayectoria). Estos complementos suelen venir introducidos por preposiciones como a, hacia, hasta, desde, etc. Los verbos de movimiento no pueden combinarse con estos complementos al carecer de la idea de trayectoria.

c) Los verbos de desplazamiento cuando se combinan con estructuras locales direccionales encabezadas por la preposición por o por locuciones como a través de, conceptualizan el movimiento como un camino o trayectoria en el espacio. Los verbos de movimiento nunca representan un camino.

d) Los verbos de desplazamiento normalmente imposibilitan la combinación con complementos de lugar en donde (del tipo estar en casa, dormir en el suelo), excepto en aquellos casos en los que se trata de una localización temática o demarcadora. Sin embargo, los verbos de movimiento admiten fácilmente estos complementos de lugar.

Este reanálisis sintáctico es el responsable de que usos como *se acostó hacia alli o * se acostaron (sin decir hacia dónde) sean imposibles con el prototipo $\mathrm{E}$; estos valores direccionales terminarán desapareciendo a medida que se imponen los valores de movimiento sin trayectoria, por lo que acostarse pasará a tener desde el siglo XVII (a excepción de determinados usos del significado $\mathrm{D}$ ) sólo las propiedades sintácticas de los verbos de movimiento.

Pero además de este reanálisis, la evolución semántica de acostarse comporta otro cambio sintáctico muy interesante, que muestra hasta qué punto están indisociablemente unidas la sintaxis y la semántica; se trata de la creación de una estructura regida en el significado G. En efecto, cuando acostarse significa mantener relaciones sexuales con alguien, exige un suplemento con la preposición con, que representa a la persona con la que se acuesta el sujeto. Este suplemento tiene la forma de un CC Comitativo o de Compañía; lo que sucede es que esa compañía es tan imprescindible con el significado $G$ (puesto que el amante es un verdadero coautor de la acción) que al final se hace obligatoria, por lo que el complemento que la expresa se convierte en un complemento o actante obligatorio exigido por la semántica del verbo, con lo que deja de ser un simple complemento circunstancial ${ }^{19}$. Los siguientes cuadros muestran visualmente las dos conceptualizaciones que ha tenido acostarse y los diferentes cambios que ha experimentado:

19 Además, con el significado $\mathrm{G}$ es muy habitual que aparezca junto al verbo el dual juntos, lo que vuelve a poner de manifiesto la importancia de la presencia de los dos participantes para que la acción pueda llevarse a cabo. Como vemos, este significado ilustra muy bien la relación sinérgica entre sintaxis y semántica que defiende la lingüística cognitiva, y es un ejemplo muy claro de iconicidad gramatical. Para estas cuestiones véase el libro de Haiman (1985). 


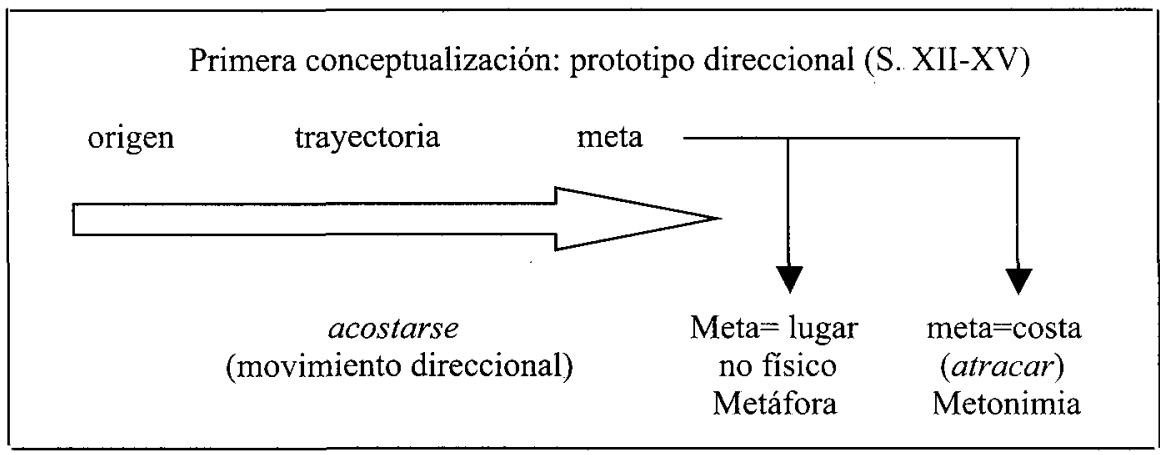

Segunda conceptualización: prototipo no direccional (S. XV-XX)

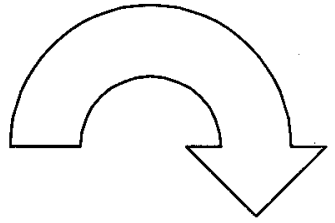

acostarse

(movimiento sin trayectoria)

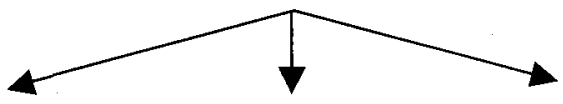

acostarse

(ladearse, inclinarse)

Metonimias acostar algo

$o$ a alguien acostarse con alguien (exige suplemento con con)

Metonimia

Tabla 4. Conceptualizaciones de acostarse.

\section{Conclusiones}

En este trabajo hemos querido aplicar los fundamentos de la semántica cognitiva diacrónica al análisis de un verbo concreto, y a la vista de los resultados, pensamos que las teorías cognitivas sobre el cambio semántico que desarrolló y sistematizó Geeraerts en su libro de 1997 son un marco teórico idóneo para establecer la evolución semántica de cualquier categoría lingüística de un modo riguroso y exhaustivo. Hemos observado cómo acostarse surge desde el latín como un verbo de movimiento direccional y cómo, a partir de este primer prototipo semántico, van a surgir otros significados (carácter dinámico de las categorías), motivados por efectos metafóricos y metonímicos y por la presión del entorno (carácter enciclopédico de la semántica). Uno de estos nuevos significados (el de tumbarse) 
acabará imponiéndose en el siglo XV, y se convertirá en el nuevo núcleo de la categoría (cambio de prototipo), con lo que acabarán desapareciendo los significados direccionales, a excepción del significado D (atracar) que pervivirá en determinados contextos. También hemos podido constatar que la evolución semántica de acostarse es paralela a su evolución sintáctica (dado que la conceptualización une ambos niveles); ésta se caracteriza fundamentalmente por el reanálisis de nuestro verbo, que pasará de ser un verbo de dirección a ser un verbo de movimiento sin trayectoria.

En definitiva, pensamos que el cognitivismo es un paradigma adecuado para analizar el lenguaje y su evolución, por cuanto parte de conceptos cognitivos y mentales básicos, que son los que regulan nuestra forma de comprender la realidad y de conceptualizarla; si no tenemos en cuenta que pensamos de un modo metafórico y metonímico y que las realidades son siempre caóticas y confusas (idea de prototipo dentro de una categoría no discreta), muy dificilmente podremos explicar los saltos evolutivos que se dan en las lenguas y las aparentes contradicciones que hallamos al estudiar su semántica.

\section{Referencias bibliográficas}

Batsiukova, V. (2004): "Verbos de movimiento en ruso y español: una vez más sobre la intransitividad dividida". En Cifuentes Honrubia, J. L. y C. Marimón Llorca (eds.): Estudios de Lingüística: el verbo. Alicante, Universidad de Alicante, págs. 11-42.

Cifuentes Honrubia, J. L. (1990): "La polisemia como prototipo diacrónico", Anales de Filología Hispánica, 5, págs. 99-119

Cifuentes Honrubia, J. L. (1994): Gramática Cognitiva. Fundamentos críticos. Madrid, Eudema.

Cifuentes Honrubia, J. L. (1999): "Movimiento, desplazamiento y cambio de lugar: aspectos sintáctico-semánticos". En Fernández González J. et alii (eds.): Lingüistica para el siglo XXI. Vol. I. Salamanca, Universidad de Salamanca, págs. 435-443

Cuenca, M. J. y J. Hilferty (1999): Introducción a la lingüistica cognitiva. Barcelona, Ariel.

Fernández Jaén, J. (en prensa): "Breve historia de la semántica histórica", Interlingüistica, 17.

Garachana, M. y J. Hilferty (1994): "Una representación de la polisemia en diacronía y sincronía", Anuari de Filologia, 17, (F-5), págs. 71-92.

García Jurado, F. (2003): Introducción a la semántica latina. De la semántica tradicional al cognitivismo. Cuadernos de Filología Clásica, Estudios latinos, Universidad Complutense de Madrid.

García Jurado, F. (2006): "Estructura léxica y construcción conceptual: Lenguas antiguas y modernas". En De Miguel, E. et alii (eds.): Estructuras Léxicas y Estructura del Léxico. Frankfurt, Peter Lang, págs. 201-223.

Geeraerts, D. (1997): Diachronic prototype semantics. A contribution to Historical Lexicology. Oxford, Oxford University Press.

Haiman, J. (1985): Natural syntax. Iconicity and erosion. Cambridge, Cambridge University Press. Kleiber, G. (1990): La sémantique du prototype. Catégories et sens lexical. París, Presses Universitaires de France.

Lakoff, G. y M. Johnson (1986): Metáforas de la vida cotidiana. Madrid, Cátedra.

Langacker, R. W. (1987): Foundations of cognitive grammar Vol. I. Theoretical Prerequisites. Stanford, Stanford University Press.

Langacker, R. W. (1991): Foundations of cognitive grammar Vol. II. Descriptive Application. Stanford, Stanford University Press.

Le Clerc, C. (1998): "Complémentarité des méthodes de sémantique structurale et de sémantique prototypique illustrée dans le champ lexical des verbes de lumière français”. En Wotjak, G. (ed.): Teoria del campo y semántica léxica. Frankfurt, Peter Lang, págs. 209-232. 
Martines Peres, J. (2000): "L'expressió de les emocions i la creativitat lèxica: estimar/amar, entre I'eufemisme i la metàfora cultural". En Actas del VIII Congreso Internacional de la Asociación Hispánica de Literatura Medieval, Vol. 2. Santander, Universidad Menéndez Pelayo, págs. 1221 1243.

Montoro Montalbán, R. M. y J. L. Cifuentes Honrubia (1995-1996): "Relaciones cognitivas de doble proceso en verbos parasintéticos", Pragmalingüistica, 3-4, págs. 449-464.

Montserrat i Buendia, S. (2004): "Evolució semàntica d'arribar en català (segies XIII-XVI): un exemple de canvi de prototipus". En Cifuentes Honrubia, J. L. y C. Marimón Llorca (eds.): Estudios de Lingüistica: el verbo. Alicante, Universidad de Alicante, págs. 421-442.

RAE (2001): Diccionario de la Lengua Española, Madrid, Espasa.

Santos Domínguez, L. A. y R. M. Espinosa Elorza (1996): Manual de semántica histórica. Madrid, Síntesis.

Soares da Silva, A. (1998): "Prototipicidad y cambio semántico: el caso ibérico de deixar/dejar". En Cifuentes Honrubia, J. L. (ed.): Estudios de Lingüistica Cognitiva, Vol. I. Alicante, Universidad de Alicante, págs. 279-294.

Soares da Silva, A. (1999): A semântica de deixar: Una contribuçao para Abordagem Cognitivo em Semântica Lexical. Braga, Fundaçao Calouste Gulbenkian, Fundaçao para a ciencia e a Tecnología.

Talmy, L. (1985): "Lexicalization patterns: semantic structure in lexical forms". In Shopen, T. (ed.): Language typology and syntactic descriptions. New York, Cambridge University Press, págs. 57149.

Ungerer, F. and H. Schmid (1996): An introduction to cognitive linguistics. London, Longman. 